http://jmscr.igmpublication.org/home/ ISSN (e)-2347-176x ISSN (p) 2455-0450

crossref DOI: https://dx.doi.org/10.18535/jmscr/v8i2.146

Journal Of Medical Science And Clinical Research

IGM Publication

An official Publication of IGM Publication

\title{
Lipoprotein lipase levels in patients with Coronary Artery Disease with Type 2 Diabetes Mellitus
}

\author{
Authors \\ Dr Sathiyanarayanan Janakiraman ${ }^{1}$, Dr Badrinath A.K ${ }^{2}$, Dr Viswanathan K.N ${ }^{3}$, \\ Dr Suresh Babu.S ${ }^{4}$, Dr Biju D.R ${ }^{5^{*}}$ \\ ${ }^{1,4}$ Assistant Professor, ${ }^{2,3}$ Professor, ${ }^{5}$ PG Resident \\ Department of General Medicine, Sri Manakula Vinayagar Medical College and Hospital, \\ Puducherry-605107, India \\ *Corresponding Author \\ Dr Biju D.R
}

\begin{abstract}
Introduction: Diabetes mellitus is a common metabolic disease. Atherosclerosis being a risk factor is promoted by decreased LPL activity which leads to elevated TG levels and reduced high density lipoprotein cholesterol (HDL-C), both risk factors for the development of coronary artery disease (CAD).

So we studied the Lipoprotein lipase levels in patients with Coronary Artery Disease and in patients with Type 2 Diabetes Mellitus and comparing it with non diabetic individuals.

Objective: To determine Lipoprotein lipase levels in patients with Coronary Artery Disease with Type 2 Diabetes Mellitus.

Methodology: We conducted a hospital based comparative cross sectional study by dividing the patients into three groups. We compared the lipoprotein lipase levels in controls and in patients with diabetes mellitus and coronary artery disease.

Results: The mean lipoprotein lipase levels in controls were 46.2 but in patients with diabetes mellitus the mean lipoprotein lipase levels were reduced to 27.5 and in patients with diabetes and coronary artery disease it was further reduced to 17.5 with $p$ value $<0.001$ which is statistically significant.

Conclusion: Reduced levels of lipoprotein lipase levels were seen in patients with coronary artery disease establishing the possible role of lipoprotein lipase in the pathogenesis of atherosclerosis.

Keywords: Lipoprotein lipase level (LPL), Diabetes mellitus and coronary artery disease.
\end{abstract}

\section{Introduction}

Diabetes mellitus, commonly known as diabetes, is a metabolic disease that causes high blood sugar. ${ }^{1}$ A person with diabetes has a condition in which the quantity of glucose in the blood is too elevated (hyperglycemia). This is because the body does not produce enough insulin, produces no insulin or has cells that do not respond properly to the insulin the pancreas produces. Diabetes is known to accelerate the process of atherosclerosis. $^{2}$ Coronary artery disease is a major public health issue in developing countries. CAD develops when the major blood vessels that supplies the heart (coronary arteries) are occluded by cholesterol containing plaques. Eventually, the decreased blood flow causes myocardial tissue necrosis presenting as a spectrum of chronic stable angina, unstable angina, Non ST elevation 
myocardial infarction and ST elevation myocardial infarction. ${ }^{3}$

Triacylglycerol (TAG) is transported in the circulation in the form of large multi-molecular lipoprotein particles. Dietary TAG and fat-soluble vitamins are packaged into chylomicrons by the intestine, whilst endogenously synthesized TAG is secreted by the liver as VLDL particles. ${ }^{3}$ Both classes of lipoprotein enter the circulation in order to distribute TAG to tissues also preventing the dispersal of the lipid en route by exchange or diffusion, the lipoproteins also confer the ability to deliver lipids to specific target tissues. LPL plays a crucial role in lipid metabolism and transport by catalysing the rate-limiting step in the hydrolysis of the TAG component present in the circulation $^{3}$. Endothelial dysfunction is widely regarded as the initial lesion in the development of atherosclerosis.LPL has also been found to play key roles in a number of physiological and pathophysiological conditions, with abnormal LPL expression or function being associated either directly or indirectly with atherosclerosis. ${ }^{4}$ Given the importance of LPL in physiological and patho-physiological changes there are various techniques available to measure lipoprotein lipase activity. Hence this study was done to know the lipoprotein lipase activity in patients with diabetes mellitus and coronary artery disease while comparing them with normal individuals.

\section{Materials and Methods}

\section{Study area and design}

This study was done at sri manakula vinayagar medical college and hospital from march to august 2019 for a period of six months after getting informed consent from patients. Sri manakula vinayagar medical college is a tertiary care hospital located at madagadipet, Puducherry. The study design employed was a hospital based cross sectional study.

\section{Study Participants}

Sample size was calculated to be 60 (20 in each group) using the software Open Epi version 3.0 taking into consideration from the previous study with $95 \%$ confidence interval and $80 \%$ power. Study participants Study participants were categorised into three groups Group A Individuals of age group 30 to 65 years without Coronary artery disease, without Diabetes Mellitus. Group B Patients diagnosed to have Coronary Artery Disease in the age group of 30-65 years admitted as inpatients in Sri Manakula Vinayagar Medical College and Hospital, Puducherry. Group C Patients diagnosed to have Type 2 Diabetes Mellitus in the age group of 30-65 years admitted as inpatients in Sri Manakula Vinayagar Medical College and Hospital, Puducherry.

All patients with Type 2 Diabetes Mellitus with Dyslipidemia and Coronary Artery Disease aged between 30-65 years were included in the study.

\section{Methodology}

After identifying these patients, questionnaire would be used to collect data from them with proper informed consent. Blood sample of $5 \mathrm{ml}$ will be collected for estimation of fasting plasma glucose, post prandial glucose, HbA1C, renal function test, lipid profile and urine sample will be analyzed for urine routine examination. 12 lead ECG, 2D echocardiography and coronary angiogram. Serum lipoprotein lipase levels were measured using Elisa kit.

\section{Statistical analysis}

Data was entered into Microsoft excel data sheet and was analyzed using SPSS $22 \mathrm{~m}$ version software. Categorical data was represented in the form of Frequencies and proportions. Chi-square test was used as test of significance for qualitative data. Continuous data was represented as mean and standard deviation. $\mathrm{p}$ value (Probability that the result is true) of $<0.05$ was considered as statistically significant after assuming all the rules of statistical tests.

MS Excel and MS word was used to obtain various types of graphs such as bar diagram, Pie diagram. SPSS version 22 (IBM SPSS Statistics, Somers NY, USA) was used to analyze data. 
Results

Table 1: Gender distribution of study participants

\begin{tabular}{|c|c|c|c|c|c|c|c|}
\hline \multirow{2}{*}{ P value } & \multicolumn{2}{|c|}{ Group 3 } & \multicolumn{2}{c|}{ Group 2 } & \multicolumn{2}{c|}{ Group 1 } & \multirow{2}{*}{ Gender } \\
\hline \multirow{4}{*}{$\mathbf{0 . 2 3 3}$} & $\mathbf{\%}$ & $\mathbf{n}$ & $\mathbf{\%}$ & $\mathbf{n}$ & $\mathbf{\%}$ & $\mathbf{n}$ & \\
\cline { 2 - 8 } & 75.0 & 15 & 50.0 & 10 & 55.0 & 11 & Male \\
\cline { 2 - 8 } & 25.0 & 5 & 50.0 & 10 & 45.0 & 9 & Female \\
\cline { 2 - 8 } & & $\mathbf{2 0}$ & & $\mathbf{2 0}$ & & $\mathbf{2 0}$ & Total \\
\hline
\end{tabular}

Group 1-Controls, Group 2- Diabetes, Group-3 Diabetes with CAD

Table 2: Distribution of study participants by diabetes

\begin{tabular}{|c|c|c|c|c|c|c|c|}
\hline P value & \multicolumn{2}{|c|}{ Group 3 } & \multicolumn{2}{c|}{ Group 2 } & \multicolumn{2}{c|}{ Group 1 } & \multirow{2}{*}{ Diabetes } \\
\hline \multirow{4}{*}{$<$} & $\mathbf{\%}$ & $\mathbf{n}$ & $\mathbf{\%}$ & $\mathbf{n}$ & $\mathbf{\%}$ & $\mathbf{n}$ & \\
\cline { 2 - 8 } & 100.0 & 20 & 100.0 & 20 & 0 & 0 & Yes \\
\cline { 2 - 8 } & 0 & 0 & 0 & 0 & 100.0 & 20 & No \\
\cline { 2 - 8 } & & $\mathbf{2 0}$ & & $\mathbf{2 0}$ & & $\mathbf{2 0}$ & Total \\
\hline
\end{tabular}

Group 1-Controls, Group 2- Diabetes, Group-3 Diabetes with CAD

Table 3: Distribution of study participants by hypertension status

\begin{tabular}{|c|c|c|c|c|c|c|c|}
\hline \multirow{2}{*}{ P value } & \multicolumn{2}{|c|}{ Group 3 } & \multicolumn{2}{c|}{ Group 2 } & \multicolumn{2}{c|}{ Group 1 } & \multirow{2}{*}{ Hypertension } \\
\hline \multirow{4}{*}{0.002} & \% & $\mathbf{n}$ & $\mathbf{\%}$ & $\mathbf{n}$ & $\mathbf{\%}$ & $\mathbf{N}$ & \\
\cline { 2 - 7 } & 40.0 & 8 & 45.0 & 9 & 0 & 0 & Yes \\
\cline { 2 - 7 } & 60.0 & 12 & 55.0 & 11 & 100.0 & 20 & No \\
\cline { 2 - 7 } & & $\mathbf{2 0}$ & & $\mathbf{2 0}$ & & $\mathbf{2 0}$ & Total \\
\hline
\end{tabular}

Group 1-Controls, Group 2- Diabetes, Group-3 Diabetes with CAD

Table 4: Distribution of study participants by alcohol status

\begin{tabular}{|l|c|c|c|c|c|c|l|}
\hline \multirow{2}{*}{ P value } & \multicolumn{2}{|c|}{ Group 3 } & \multicolumn{2}{c|}{ Group 2 } & \multicolumn{2}{c|}{ Group 1 } & \multirow{2}{*}{ Alcohol } \\
\hline \multirow{4}{*}{$\mathbf{0 . 0 3 2}$} & $\mathbf{\%}$ & $\mathbf{n}$ & $\mathbf{\%}$ & $\mathbf{n}$ & $\mathbf{\%}$ & $\mathbf{N}$ & \\
\cline { 2 - 7 } & 25.0 & 5 & 30.0 & 6 & 0 & 0 & Yes \\
\cline { 2 - 7 } & 75.0 & 15 & 70.0 & 14 & 100.0 & 20 & No \\
\cline { 2 - 7 } & & $\mathbf{2 0}$ & & $\mathbf{2 0}$ & & $\mathbf{2 0}$ & Total \\
\hline
\end{tabular}

Group 1-Controls, Group 2- Diabetes, Group-3 Diabetes with CAD

Table 5: Distribution of study participants by smoking status

\begin{tabular}{|l|c|c|c|c|c|c|l|}
\hline \multirow{2}{*}{ P value } & \multicolumn{2}{|c|}{ Group 3 } & \multicolumn{2}{c|}{ Group 2 } & \multicolumn{2}{c|}{ Group 1 } & \multirow{2}{*}{ Smoking } \\
\hline \multirow{4}{*}{$\mathbf{0 . 0 0 6}$} & $\mathbf{\%}$ & $\mathbf{n}$ & $\mathbf{\%}$ & $\mathbf{n}$ & $\mathbf{\%}$ & $\mathbf{N}$ & \\
\cline { 2 - 7 } & 40.0 & 8 & 35.0 & 7 & 0 & 0 & Yes \\
\cline { 2 - 7 } & 60.0 & 12 & 65.0 & 13 & 100.0 & 20 & No \\
\cline { 2 - 7 } & & $\mathbf{2 0}$ & & $\mathbf{2 0}$ & & $\mathbf{2 0}$ & Total \\
\hline
\end{tabular}

Group 1-Controls, Group 2- Diabetes, Group-3 Diabetes with CAD

Table 6: Random blood sugar level of study participants in different groups

\begin{tabular}{|c|c|c|c|}
\hline P Value & SD & Mean & Random blood sugar level \\
\hline \multirow{3}{*}{$<\mathbf{0 . 0 0 1}$} & 19.3 & 98.2 & Controls \\
\cline { 2 - 4 } & 74.5 & 263.8 & Diabetes \\
\cline { 2 - 4 } & 57.2 & 228.7 & Diabetes with Coronary artery disease \\
\hline
\end{tabular}




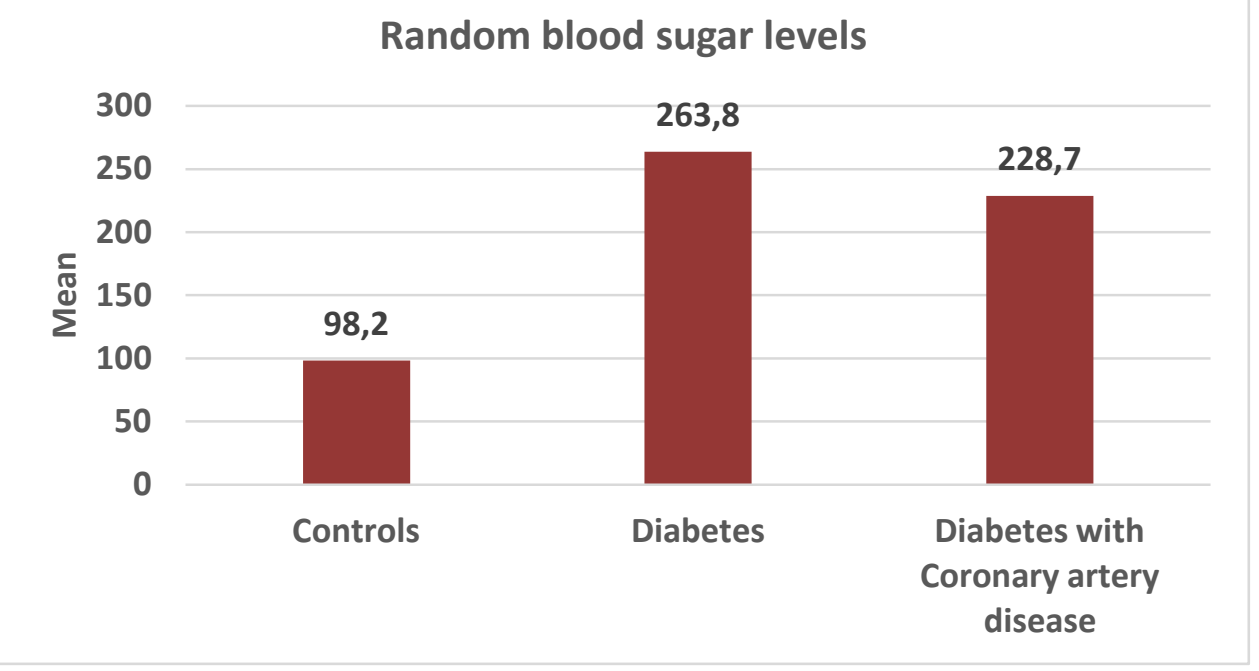

Table 7: BMI level of study participants in different groups

\begin{tabular}{|c|c|c|c|}
\hline P Value & SD & Mean & BMI \\
\hline \multirow{3}{*}{0.002} & 1.2 & 22.6 & Controls \\
\cline { 2 - 4 } & 2.4 & 25.0 & Diabetes \\
\cline { 2 - 4 } & 2.4 & 23.7 & Diabetes with Coronary artery disease \\
\hline
\end{tabular}

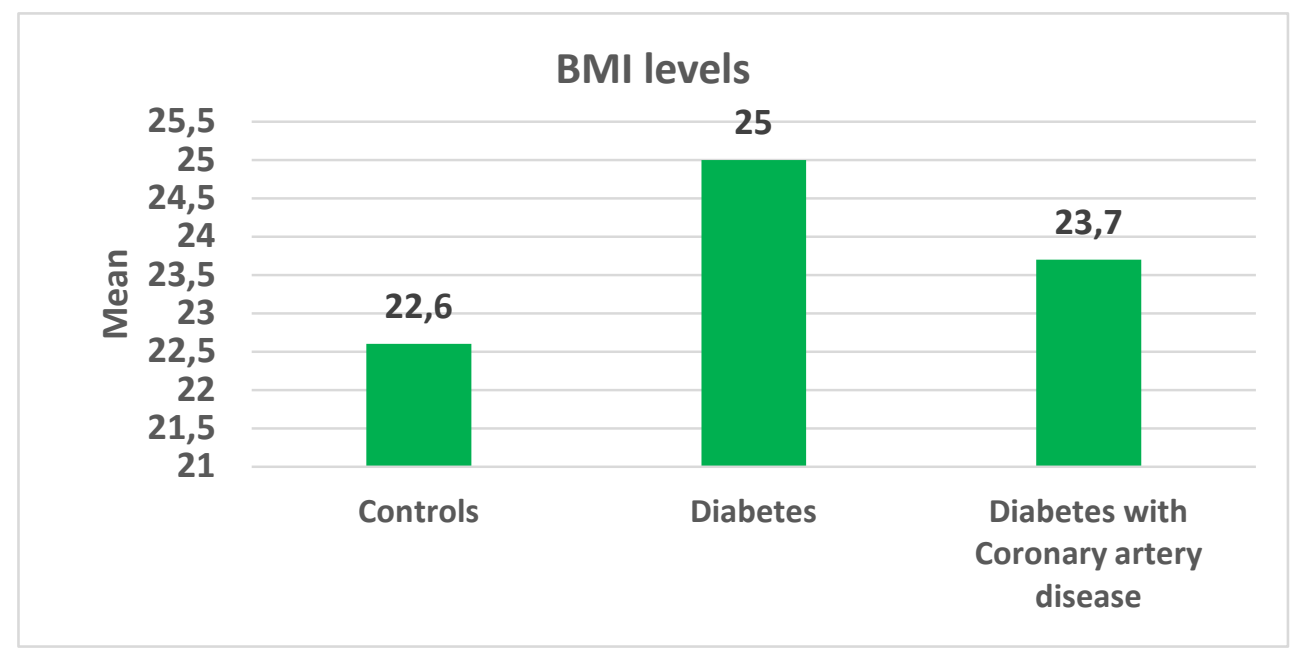

Table 8: GFR level of study participants in different groups

\begin{tabular}{|l|c|c|l|}
\hline P Value & SD & Mean & GFR \\
\hline \multirow{3}{*}{$<\mathbf{0 . 0 0 1}$} & 10.8 & 100.8 & Controls \\
\cline { 2 - 4 } & 18.6 & 83.8 & Diabetes \\
\cline { 2 - 4 } & 21.4 & 77.9 & Diabetes with Coronary artery disease \\
\hline
\end{tabular}

\section{Glomerular filtration rate}
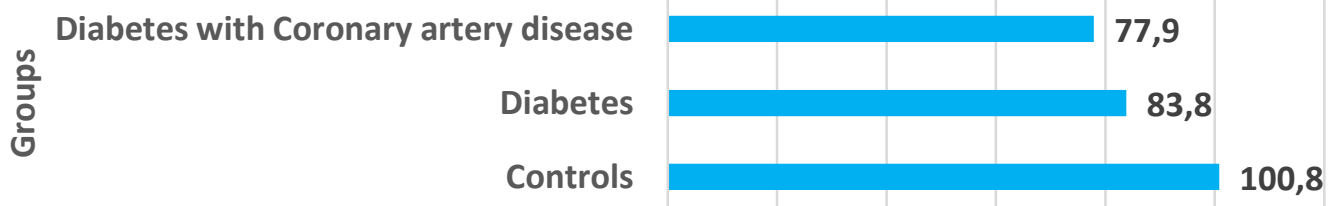

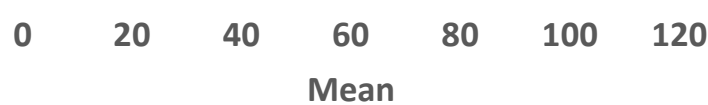




\section{JMSCR Vol||08||Issue||02||Page 857-864||February}

Table 9: Non- HDL level of study participants in different groups

\begin{tabular}{|c|c|c|c|}
\hline P Value & SD & Mean & Non HDL \\
\hline \multirow{3}{*}{0.04} & 25.9 & 126.1 & Controls \\
\cline { 2 - 4 } & 37.2 & 157.0 & Diabetes \\
\cline { 2 - 4 } & 47.2 & 141.9 & Diabetes with Coronary artery disease \\
\hline
\end{tabular}

Non-HDL Levels

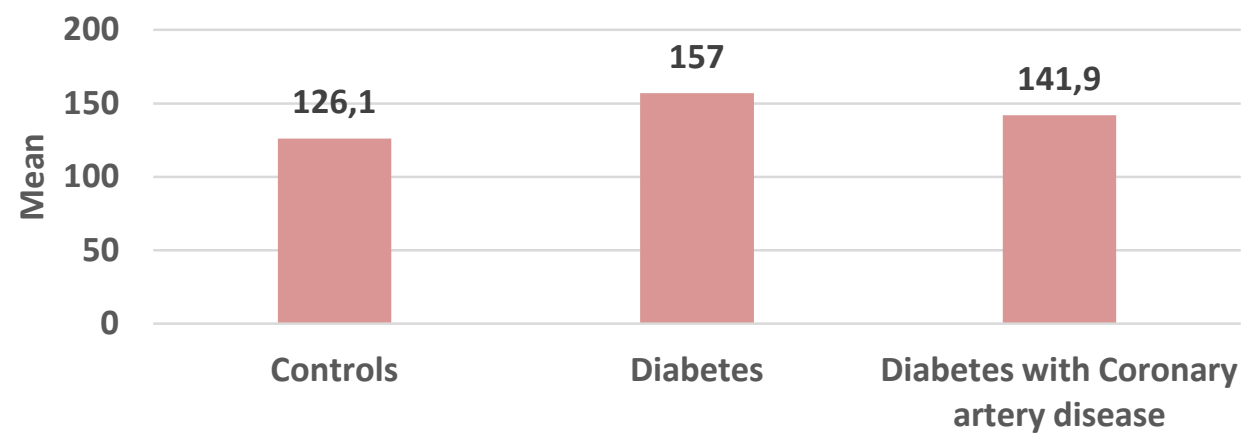

Table 10: TC/HDL ratio of study participants in different groups

\begin{tabular}{|c|c|c|c|}
\hline P Value & SD & Mean & TC/HDL \\
\hline \multirow{3}{*}{$<\mathbf{0 . 0 0 1}$} & 0.6 & 4.0 & Controls \\
\cline { 2 - 4 } & 1.1 & 5.4 & Diabetes \\
\cline { 2 - 4 } & 1.1 & 5.1 & Diabetes with Coronary artery disease \\
\hline
\end{tabular}

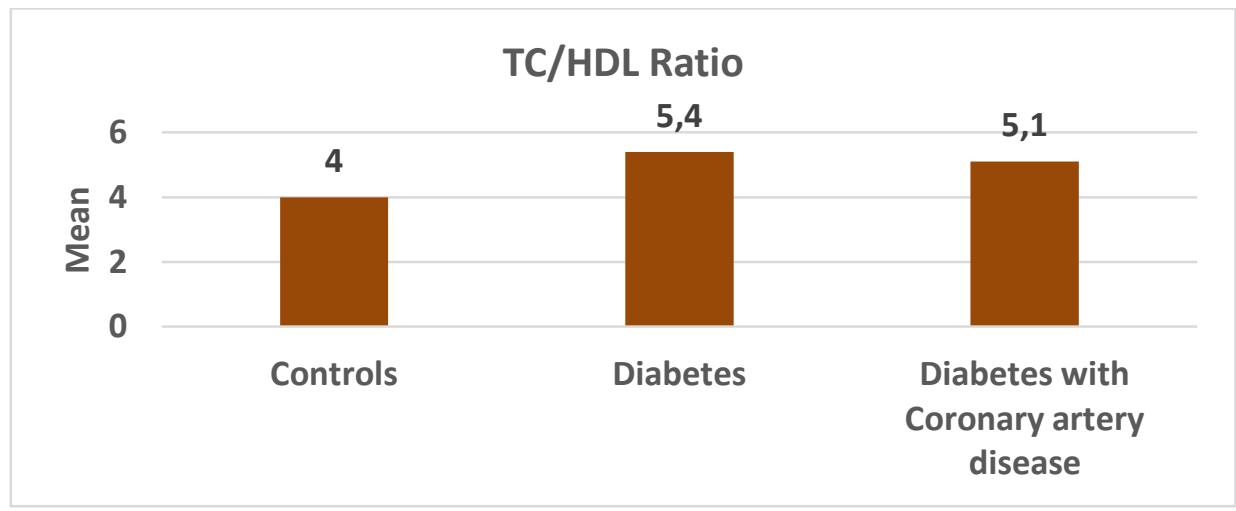

Table 11: LDL/HDL level of study participants in different groups

\begin{tabular}{|c|c|c|c|}
\hline P Value & SD & Mean & LDL/HDL \\
\hline \multirow{3}{*}{0.01} & 0.6 & 2.5 & Controls \\
\cline { 2 - 4 } & 0.8 & 3.3 & Diabetes \\
\cline { 2 - 4 } & 0.8 & 3.1 & Diabetes with Coronary artery disease \\
\hline
\end{tabular}

\section{LDL/HDL Ratio}

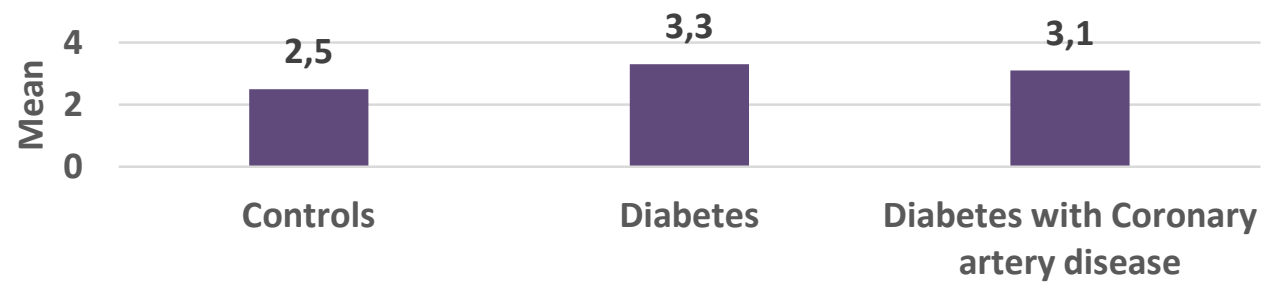


Table 12: Lipoprotein lipase level of study participants in different groups

\begin{tabular}{|c|c|c|c|}
\hline \multirow{2}{*}{ P Value } & SD & Mean & LPL \\
\hline \multirow{3}{*}{$<\mathbf{0 . 0 0 1}$} & 2.1 & 46.2 & Controls \\
\cline { 2 - 4 } & 3.7 & 27.5 & Diabetes \\
\cline { 2 - 4 } & 3.3 & 17.5 & Diabetes with Coronary artery disease \\
\hline
\end{tabular}

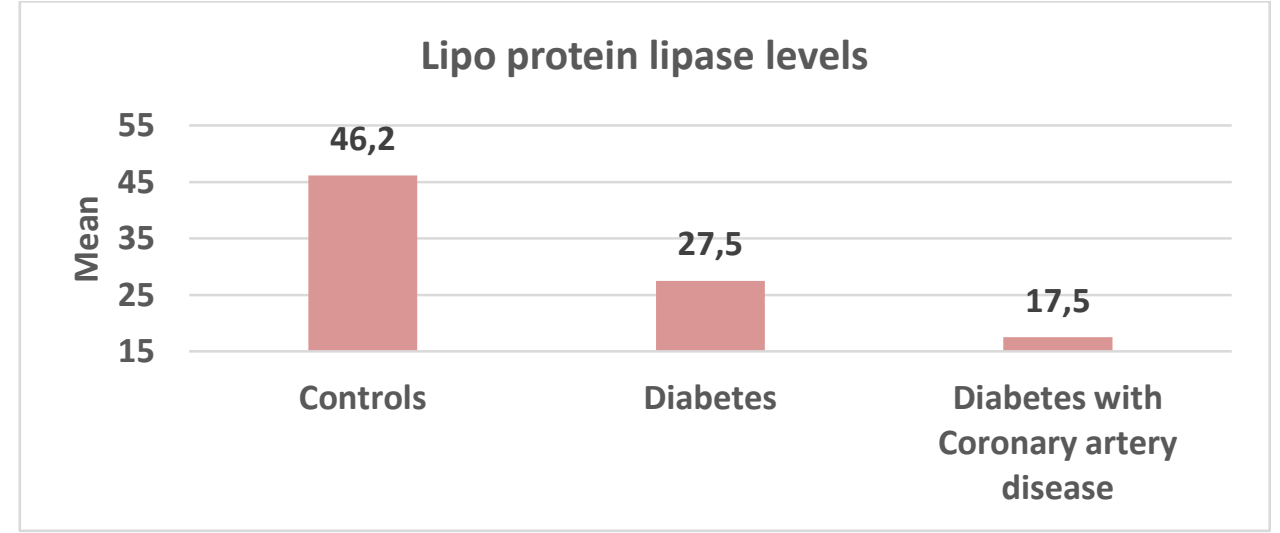

Table 13: Correlation of LPL with other parameters

\begin{tabular}{|c|c|c|c|}
\hline P value & Correlation coefficient (r) & Parameter 2 & Parameter 1 \\
\hline 0.14 & -0.19 & Non-HDL & LPL \\
\hline $\mathbf{0 . 0 0 1}$ & -0.43 & TC/ HDL & LPL \\
\hline $\mathbf{0 . 0 0 7}$ & -0.34 & LDL/HDL & LPL \\
\hline $\mathbf{0 . 0 3}$ & -0.27 & TG/HDL & LPL \\
\hline
\end{tabular}

\section{Discussion}

Lipoprotein lipase levels are reduced in patients with diabetes mellitus. Patients with diabetes are at increased risk of developing coronary artery disease due to increased risk of atherosclerosis. The crucial role of LPL in lipid metabolism is illustrated by genetic LPL deficiency a rare disorder characterized by severe hypertriglyceridemia and low HDL cholesterol (HDL-C) levels. ${ }^{5}$

In this study we observed a male preponderance of $60 \%$ due to associated comorbidities of smoking and diabetes mellitus. The control group had no risk factors in terms of diabetes, systemic hypertension, smoking or alcohol usage. While the diabetic and CAD groups included individuals with the above mentioned risk factors. There were no significant differences in coronary risk factors such as hypertension, diabetes mellitus, smoking and body mass index as seen in a study done by takashi in Japanese population. ${ }^{6}$

We also wanted to know the renal function in the three groups by calculating the estimated glomerular filtration rate between the three groups. The control population had a mean e-GFR of 100.8 while patients with diabetes had a mean e-GFR of 83.8 and diabetic with coronary artery disease population had a e-GFR of 77.9 with a $p$ value of $<0.001$ which is statistically significant. This finding is similar to other studies where diabetes and coronary artery disease in combination has shown to reduce the renal function. $^{7,8}$

In agreement with previous studies, we observed that coronary artery disease is strongly associated with diabetes HDL-C, TGL, TC and LDL-C levels. ${ }^{9,10}$ However there were no significant differences of lipid profile while comparing them between the three groups. In this study, we also compared the non-HDL levels, TC/HDL, LDL/HDL ratios between the three groups and it was statistically significant with a $p$ value $<0.001$. In addition to finding the ratios of non-HDL, TC/HDL, LDL/HDL, TG/HDL we co-related these variables with lipoprotein lipase levels among the three groups and there were no significant correlation seen. ${ }^{11,12}$ However this study shows the inverse relation of lipoprotein 


\section{JMSCR Vol||08||Issue||02||Page 857-864||February}

lipase levels in patients with diabetes and coronary artery disease. The mean lipoprotein lipase levels in controls were 46.2 and in diabetic group it was reduced to 27.5 and it was further reduced to17.5 in diabetics with coronary artery disease group, thus establishing the inverse correlation of lipoprotein lipase

Co-relation scatter plot

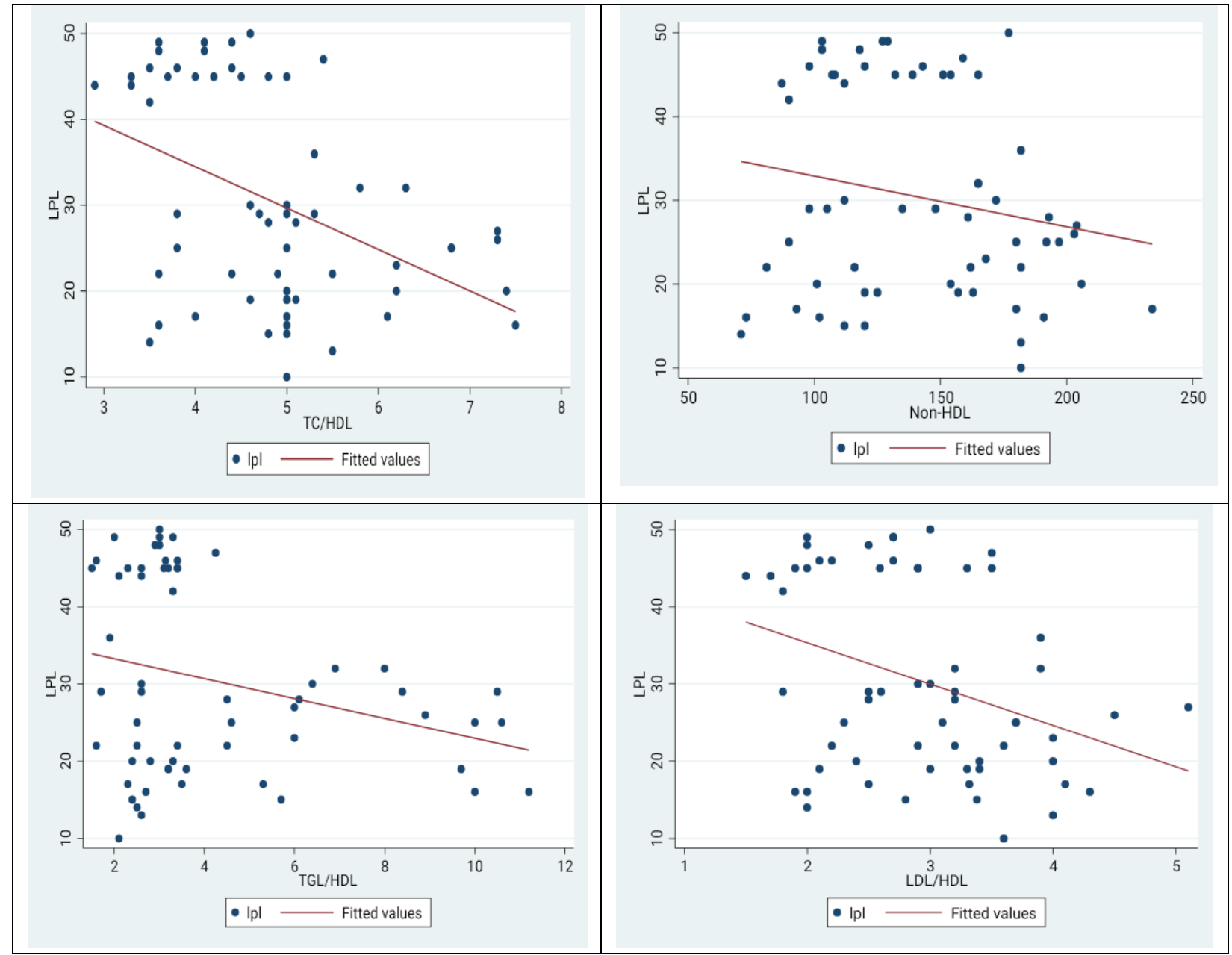

\section{Limitations}

Less statistical power due to small study population. All patients with dyslipidemia irrespective of statin therapy were taken in the study which could have impacted the fasting lipid profile.

\section{Conclusion}

In patients with diabtetes and coronary artery disease lipoprotein lipase levels were significantly reduced and high levels of lipoprotein lipase could be atheroprotective thus explaining the possible role of lipoprotein lipase in the process of atherosclerosis in diabetes and CAD population.

\section{References}

1. Goldberg IJ, Merkel M. Lipoprotein lipase: physiology, biochemistry and molecular biology. Front Biosci. 2001;6:D388-D405.

2. Beisiegel $U$, Weber $W$, BengtssonOlivecrona G. Lipoprotein lipase enhances the binding of chylomicrons to low density lipoprotein receptor related protein. ProcNatl Acad Sci U S A. 1991;88:83428346.

3. Hitsumoto $\mathrm{T}$, Yoshinaga $\mathrm{K}$, Aoyagi $\mathrm{K}$, Sakurai T, Kanai M, Uchi T,Noike H, Ohsawa H, Watanabe H, Shirai K. Association between preheparinserum lipoprotein lipase mass and acute 
myocardial infarction in Japanese men. J Atherosclerosis. 2002;9:163-169.

4. Dugi KA, Schmidt N, Brandauer K, Ramacher D, Fiehn W, Kreuzer J.Activity and concentration of lipoprotein lipase in post-heparin plasmaand the extent of coronary artery disease. Atherosclerosis. 2002;163:127-134.

5. Henderson HE, Kastelein JJ, Zwinderman AH, Gagne E, Jukema JW,Reymer PW, Groenemeyer BE, Lie KI, Bruschke AV, Hayden MR,Jansen H. Lipoprotein lipase activity is decreased in a large cohort of patients with coronary artery disease and is associated with changes inlipids and lipoproteins. J Lipid Res. 1999;40:735-743

6. Gordon DJ, Probstfield JL, Garrison RJ, Neaton JD, Castelli WP, Knoke JD et al, High-density lipoprotein cholesterol and cardiovascular disease. Four prospective American studies. Circulation 1989 Jan 1;79(1):8-15.

7. Camont L, Chapman MJ, Kontush A. Biological activities of HDL subpopulations and their relevance to cardiovascular disease. Trends in molecular medicine. 2011 Oct 31;17(10):594-603.

8. Tian L, Fu M. The relationship between high density lipoprotein subclass profile and plasma lipids concentrations. Lipids in health and disease. 2010 Oct 17;9(1):118

9. Natarajan P, Ray KK, Cannon CP. Highdensity lipoprotein and coronary heart disease: current and future therapies. Journal of the American College of Cardiology. 2010Mar 30;55(13):1283-99.
10. Pirillo A, Norata GD, Catapano AL. Highdensity lipoprotein subfractions-what the clinicians need to know. Cardiology. 2013;124(2):116-25.

11. Xu RX, Zhang Y, Ye P, Chen H, Li YF, Hua $Q$ et al. Analysis of lipoprotein subfractions in Chinese Han patients with stable coronary artery disease. Heart, Lung and Circulation. 2015 Dec 31;24(12):120310.

12. Huttunen, J. K., C. Ehnholm, M. Kekki, and E. A. Nikkila. 1976.Post-heparin plasma lipoprotein lipase and hepatic lipase in normalsubjects and in patients with hypertriglyceridaemia: correlations to sex, age and various parameters of triglyceride metabolism. Clin. Sci. Mol. Med. 50: 249260. 